\title{
Is Graduation from Social Safety Nets Possible? Evidence from Sub-Saharan Africa
}

\author{
Silvio Daidone, ${ }^{{ }_{1}}$ Luca Pellerano, Sudhanshu Handa and \\ Benjamin Davis
}

\begin{abstract}
In the last decade social cash transfer programmes have become extremely popular in sub-Saharan Africa, and are often portrayed as an instrument that can facilitate graduation out of poverty. The evidence on whether social cash transfers have had actual effects on graduation, however, is limited. This article provides a cross-country reflection of the potential effects of social cash transfers on graduation, drawing from impact evaluation results of cash transfer programmes in Ghana, Kenya, Lesotho and Zambia. We analyse whether social cash transfers have improved the likelihood of graduation, through increased productivity, income generation and resilience to shocks. We identify which factors in terms of programme implementation and household characteristics can increase the likelihood of cash transfer programmes facilitating graduation from poverty.
\end{abstract}

\section{Introduction}

The past decade has seen an exponential increase in social protection programmes. In Latin America conditional cash transfers have become the backbone of targeted social policies, while in Africa the number of social cash transfer programmes has increased tenfold since 2000 (Garcia and Moore 2012). Most of these new cash transfer programmes are unconditional.

In sub-Saharan Africa social cash transfers have often been portrayed not only as a safety net to protect and redistribute resources to the poor, but also as an instrument that can facilitate graduation out of poverty. Graduation and growth objectives have therefore been repeatedly associated with social cash transfers and more generally with social protection programmes, irrespective of the logic of whether these instruments can actually meet such multiple objectives (Slater and McCord 2009). This approach has been justified by the aspiration of donors and governments to provide assistance to the most disadvantaged segments of the population, helping them to move on a pathway out of poverty, while at the same time contributing to both micro- and macro-economic growth.

The evidence on whether unconditional cash transfers have had actual effects on graduation is limited. This is largely because most programmes are relatively young and the majority of impact evaluations only measure short-term effects, but also because most programmes lack a clear and consistent concept of graduation. Graduation means different things to various stakeholders. For some, it means exit from programmes after having reached a specific administrative benchmark that signals the point at which a beneficiary is no longer eligible (threshold graduation). To others, graduation represents a positive transformation in livelihoods (sustainable graduation), such that over time households become more resilient to different shocks and stressors (Sabates-Wheeler and Devereux 2013).

In either case, the link to measurable, verifiable sustainable livelihoods is not necessarily straightforward. Threshold graduation (for example, number of years in a programme, or a child reaching a certain age), while relatively 
easy to determine, may not have anything to do with having achieved sustainable livelihoods. Measures which focus on poverty status, level of income or consumption, or ownership of assets, are difficult to measure and are implicitly linear, suggesting a steady progression up an income or asset scale, but livelihoods in rural Africa are often erratic and uncertain. Even if a household appears to have passed an income and/or asset threshold at some point in time, it is difficult to determine whether a major shock will leave the household severely vulnerable to hunger - and off the road to graduation.

Few social protection programmes in subSaharan Africa make an explicit reference to either threshold graduation or sustainable graduation in their objectives or theory of change. Attempts to operationalise graduation strategies are complex and costly, and may be considered less of a priority when facing the challenge of the basic programme design features. However, despite not incorporating a direct measure of graduation, cash transfers by themselves have the potential to enhance the likelihood of graduating, which we define as those changes over time in livelihood strategies that show the household is on a pathway towards increasing its capacity to generate income and being more resilient to shocks.

Drawing from evaluations of four unconditional cash transfer programmes in sub-Saharan Africa, this article shows that even if social protection programmes do not have explicit graduation objectives they can facilitate progress towards graduation outcomes. We focus in particular on the productive role of cash transfer programmes: their effects on investments, labour supply and risk-coping mechanisms, as well as on the local economy.

The main working hypothesis of the article is that regular and predictable flows of cash relax liquidity, credit and/or insurance constraints faced by recipients, and in this way improve livelihood choices and productive incomegenerating investments. These impacts come through changes in individual and household behaviour (labour supply, investments and risk management) and through impacts on the local economy of communities where the transfers operate. Further, the receipt of these payments can influence recipients' role in social networks, by increasing mutually beneficial risk-sharing arrangements and economic collaboration and by greater inclusion in decision-making processes. Each of these impacts improves the sustainability of household income-generating strategies and increases the household's ability to potentially 'graduate' out of poverty.

The rest of the article is organised as follows. Section 2 provides a discussion of the main analytical results. Explanations of observed differences across and within countries are presented and discussed in Section 3, followed by the conclusions in Section 4.

\section{Impact evaluation results}

The cash transfer programme evaluations that serve as the basis of this article form part of the From Protection to Production ( $\mathrm{PtoP})$ project, a multi-country effort to analyse the economic impact of cash transfers in sub-Saharan Africa taking advantage of existing and ongoing impact evaluations. ${ }^{2}$ The project uses a mixed methods approach, combining econometric analysis based on experimental or quasi-experimental study design, general equilibrium models of the local economies and qualitative methods. We focus on government-run cash transfer programmes in four countries, each with broadly similar human development and rural poverty reduction objectives. The Kenyan Cash Transfer for Orphans and Vulnerable Children (CT-OVC) reaches over 250,000 ultra-poor households with children with bi-monthly payments of Ksh 2,000 per month (£14.10). The Child Grants Programme (CGP) in Lesotho targets 25,000 ultra-poor households with quarterly payments that range from 120 to 250 Maloti per month (£10.90 to £22.80), depending on the number of children. The Zambia Child Grant Programme (CGP) provides a fixed bi-monthly payment of 60 Kwacha per month (£10.90) to 20,000 households with young children, while the Livelihood Empowerment Against Poverty (LEAP) programme in Ghana reaches almost 77,000 extremely poor households with payments that vary by household size from 8 to 15 Cedi per month (£3.60 to $£ 6.70$ ).

We discuss the impact of the four programmes on beneficiary households over three broad groups of outcome variables: productive activities, labour allocation, and social networks and risk-coping strategies. We focus on the results from the econometric analyses and, 


\begin{tabular}{lcccc}
\hline & Zambia CGP & Kenya CT-OVC & Lesotho CGP & Ghana LEAP \\
\hline Agricultural inputs & ++ & - & ++ & + \\
\hline Agricultural tools & ++ & NS & NS & NS \\
\hline Agricultural production & + & + & + & NS \\
\hline Home production of food & NS & ++ & + & NS \\
\hline Livestock ownership & ++ & + & NS & NS \\
\hline Non-farm enterprises & ++ & NS
\end{tabular}

Source Based on AIR (2013) and Daidone et al. (2014b) for Zambia; Asfaw et al. (2013) for Kenya; Daidone et al. (2014a) for Lesotho; Handa et al. (2013) for Ghana.

Note Authors' assessment. ++: positive and significant for many indicators; +: positive and significant for one or few indicators or for specific subgroups; NS: not significant; -: negative and significant for one or few indicators or for specific subgroups. Blank cell for lack of indicators.

where applicable, we supplement the comparative analysis with results from the qualitative evidence that report on similar outcomes. Finally, we also discuss general equilibrium local economy simulations produced by the Local Economy-Wide Impact Evaluation (LEWIE) model (Taylor 2013). ${ }^{3}$

\subsection{Impacts on productive activities}

We look at various dimensions of the productive process in order to ascertain whether cash transfer programmes have led households to increase their investment in non-farm businesses and agricultural activities, including both crop and livestock production. A summary of results is provided in Table 1. Overall, cash transfer programmes have had a large impact over a variety of household productive activities, though the impacts vary by country.

In Zambia, the CGP facilitated the purchase and/or increased use of various types of agricultural inputs and assets, especially by smaller households. This led to an expansion in the overall value of crop production, which was marketed rather than consumed on-farm.

Beneficiary households also invested in a wide variety of livestock. Furthermore, beneficiary households were significantly more likely to have a non-farm business, to operate enterprises for longer periods and more profitably, and to accumulate physical capital.

In Kenya and Lesotho, households invested some of the cash for productive purposes in crop inputs and livestock, with varying magnitudes and significance. The Kenya CT-OVC increased the ownership of small ruminants by both smaller and female-headed households, while the Lesotho CGP led to an increase in pig ownership. The CGP combined with a Food Emergency Grant brought about a significant increase in the use of organic fertilisers and pesticides, particularly in households with greater labour capacity. The positive impact on input use in Lesotho led to an increase in maize and vegetable output, especially for households with more labour capacity. While the Kenya programme did not lead to an increase in crop production per se, beneficiary households increased the share of food consumption derived from own production, particularly animal products.

The LEAP programme in Ghana, with the exception of a significant increase in seeds expenditure, did not have a statistically significant impact on household productive activities, including both crop and livestock production. The qualitative fieldwork, however, did record experiences of households utilising LEAP resources in a variety of livelihood activities.

\subsection{Impacts on labour supply}

Along with increases in crop and livestock production, the four cash transfer programmes have led to changes in household labour supply. Qualitative fieldwork on these programmes consistently reports a shift from casual agricultural wage labour to on-farm and own- 


\section{Zambia CGP Kenya CT-OVC Lesotho CGP Ghana LEAP}

Adults

\begin{tabular}{lccccc}
\hline Agricultural wage labour & -- & - & -- & NS \\
\hline Non-agricultural wage labour & + & NS & & NS \\
\hline Family farm & ++ & + & + & + \\
\hline Non-farm business & ++ & & NS &
\end{tabular}

Source Based on AIR (2013) and Daidone et al. (2014b) for Zambia; Asfaw et al. (2013) for Kenya; Daidone et al. (2014a) for Lesotho; Handa et al. (2013) for Ghana.

Note Authors' assessment. ++: positive and significant for many indicators; +: positive and significant for one or few indicators or for specific subgroups; NS: not significant; -: negative and significant for one or few indicators or for specific subgroups; - -: negative and significant for many indicators. Blank cell for lack of indicators.

business activities. The picture coming from quantitative impact assessments is more complex and is summarised in Table 2. In Zambia, the CGP transfers led family members to reduce their participation in, and intensity of, agricultural wage labour. The impact was particularly strong for women, amounting to a 17 percentage point reduction in participation and 12 fewer days a year. Both men and women increased the time they spent on family agricultural and non-agricultural businesses. ${ }^{4}$ In Kenya, Lesotho and Ghana, while impacts are not significant overall, significant shifts varied by age and gender. For example, in Lesotho male participation in casual wage labour decreased, while elderly women increased their participation on-farm. In Ghana, the LEAP programme increased on-farm activities for males.

\subsection{Impacts on social networks and risk-coping strategies}

Next we look at impacts of cash transfers for various indicators concerning risk-coping strategies, social networks and saving/borrowing behaviour, for which we provide a summary in Table 3. Cash transfers have allowed beneficiary households to better manage risk in all four countries. Qualitative fieldwork in Kenya, Ghana and Lesotho suggests that the programmes increased social capital and allowed beneficiaries to re-engage with existing social networks and/or

Table 3 Impacts on risk management

\begin{tabular}{lcccc}
\hline & Zambia CGP & Kenya CT-OVC & Lesotho CGP & Ghana LEAP \\
\hline Negative risk-coping strategy & & +- & ++ \\
\hline Savings & ++ & ++ & NS & ++ \\
\hline Pay off debt & ++ & NS & NS & - \\
\hline Borrowing & -- & NS & NS \\
\hline Purchase on credit & NS & ++ & ++ \\
\hline Give informal transfers & & ++ & NS \\
\hline Receive informal transfers & & -- & NS \\
\hline Remittances & & & + \\
\hline
\end{tabular}

Source Based on AIR (2013) and Daidone et al. (2014b) for Zambia; Asfaw et al. (2013) for Kenya; Daidone et al. (2014a) for Lesotho; Handa et al. (2013) for Ghana.

Note Authors' assessment. ++: positive and significant for many indicators; +: positive and significant for one or few indicators or for specific subgroups; NS: not significant; -: negative and significant for one or few indicators or for specific subgroups; - -: negative and significant for many indicators. Blank cell for lack of indicators. 


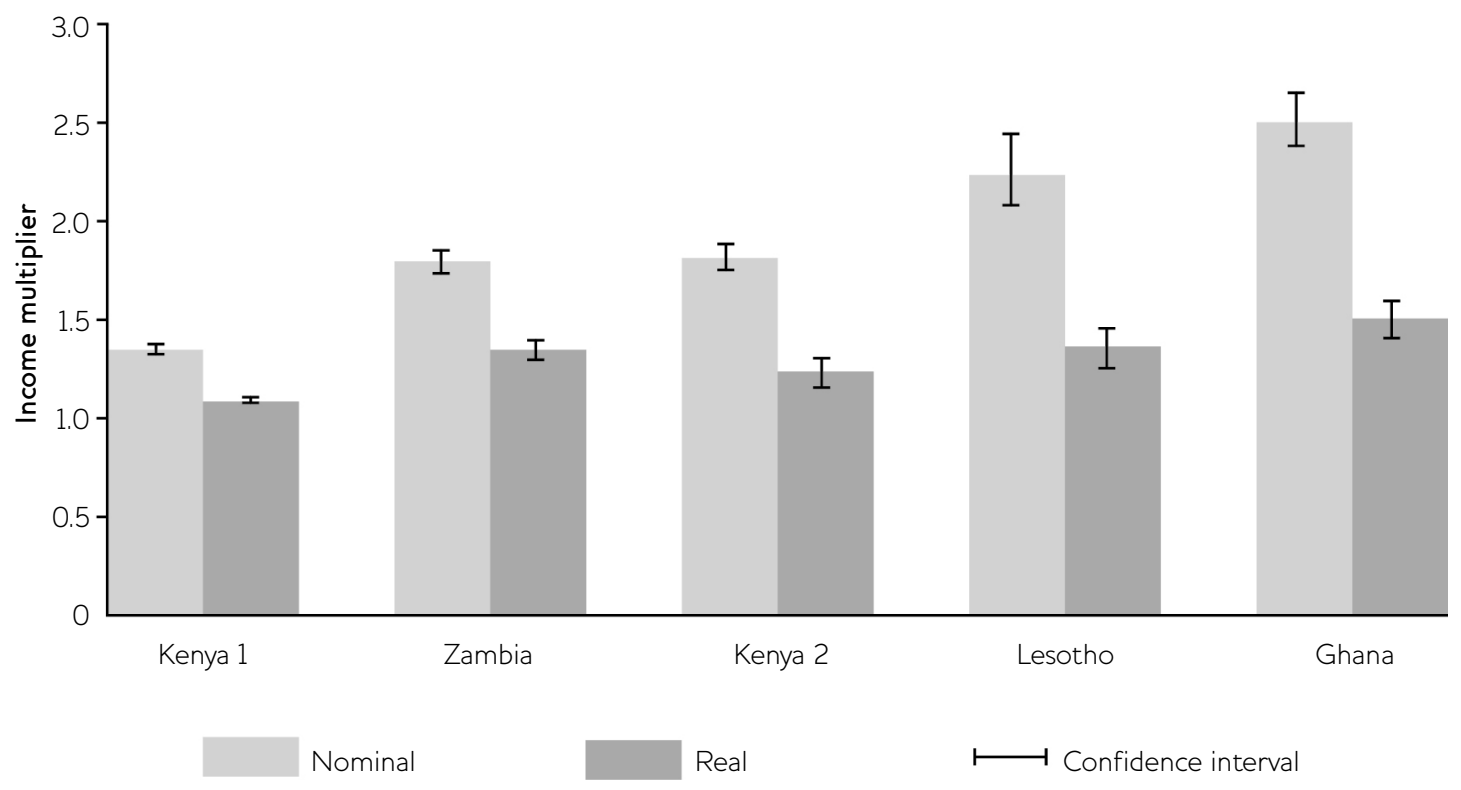

Source Authors' own.

Note Ninety per cent confidence interval; data drawn from sources cited in endnote 3.

Kenya 1 includes Nyanza district, Kenya 2 includes Garissa and Kwale.

to strengthen informal social protection systems and risk-sharing arrangements. These results were corroborated by econometric analysis in Ghana and Lesotho.

The cash transfer programmes led to a reduction in negative risk-coping strategies, such as begging or taking children out of school in Lesotho. Moreover, the cash transfer programmes led households to be seen as more financially trustworthy, allowing them to reduce their debt and increase their creditworthiness. Beneficiary households in Ghana and Zambia increased their cash savings. In many cases, however, households remain risk averse and reluctant to take advantage of their greater access to credit.

\subsection{Impacts on the local economy}

Cash transfer programmes also have significant impacts on the local economy in which they are implemented. When beneficiaries spend the cash, programme impacts are transmitted to others inside and beyond the local economy, often to households that are not eligible for cash transfers who own local businesses. These income multipliers were measured using the LEWIE village economy model, which generated nominal income multipliers for the programmes in these four countries ranging from 1.34 in Nyanza District, Kenya to 2.50 in Ghana (see Figure 1). That is, for every Cedi transferred by the programme in Ghana, up to 2.50 Cedi in income can be generated for the local economy.

When credit, capital and other market constraints limit the local supply response, however, the increase in demand may lead to higher prices and consequently a lower income multiplier. This 'real' income multiplier in our four countries is lower than the nominal income multiplier, although it remains greater than one in each case.

\section{What drives differences in impact?}

Our review of evidence on the effects on productive activities of four cash transfer programmes in sub-Saharan Africa reveals some common trends as well as contrasts across countries. The GGP programme in Zambia had a broad range of impacts across productive outcomes, while the other programmes had more selective impacts. The results provide some indication as to the conditions which enable cash transfer programmes to have a stronger effect on transforming livelihoods and increasing productive activities - which, we argue, is an important step towards sustainable graduation. 


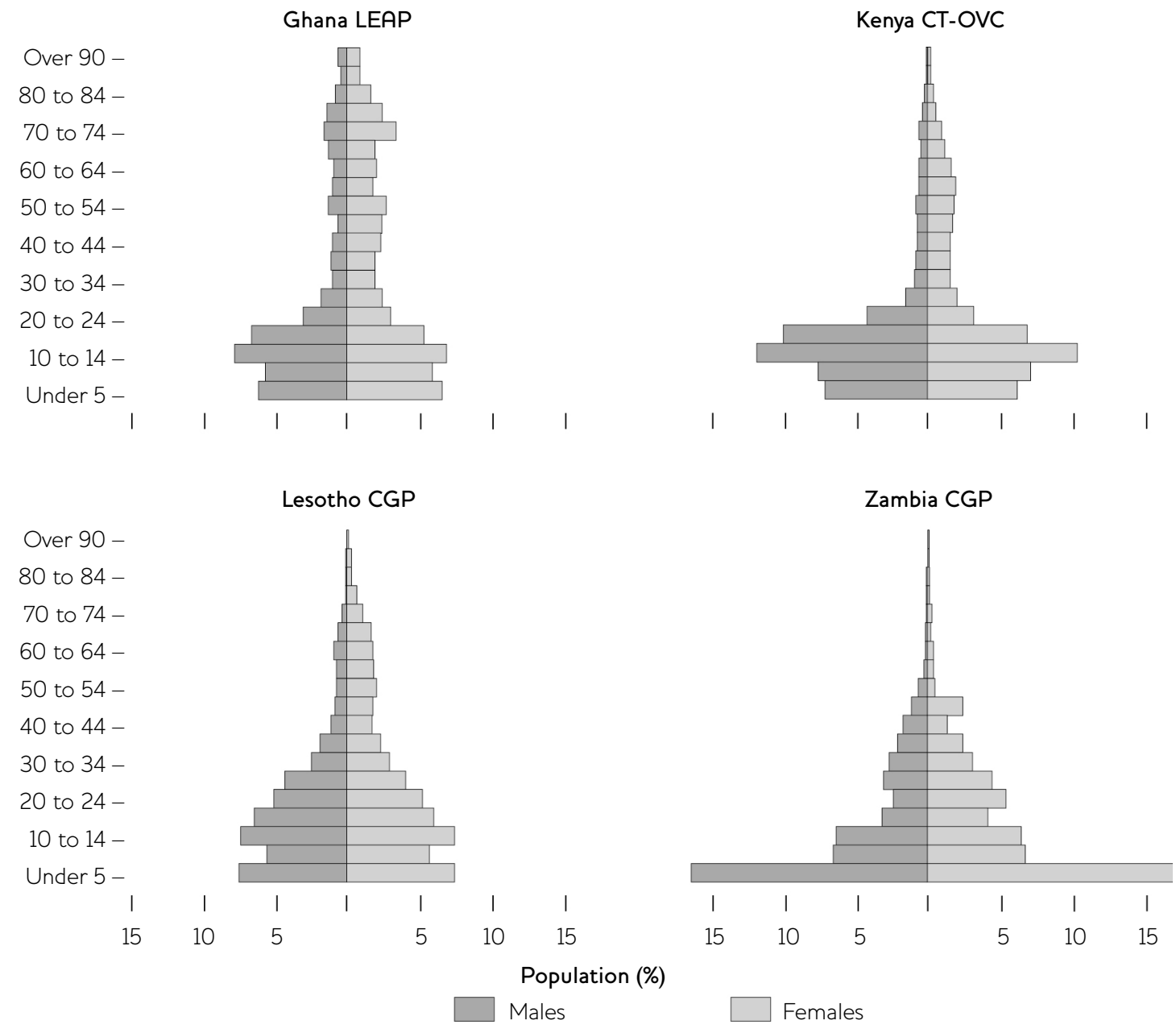

Source Authors' own.

Our analysis suggests three categories of factors.

\subsection{Household level enablers of livelihoods transformation}

A first set of conditions relates to the characteristics of households and individuals that are targeted by cash transfer programmes. In sub-Saharan Africa, one group of cash transfer programmes (for example, LEAP in Ghana) has been targeted to households that are vulnerable as well as poor, in part as a desire to reach households affected by the HIV pandemic. Vulnerability is often defined as inability to work (elderly, disabled), and/or with a high dependency ratio. In a second group of countries (such as Kenya and Lesotho) programmes have adopted a stronger focus on reducing child poverty, often mediated by the notion of orphans and vulnerable children (OVC). The Zambia GGP varies the approach; it targets households with children in a narrower age range (between 0 and 5 years), who live in households with relatively younger parents.

The adoption of different targeting criteria had strong implications for the demographic characteristics of beneficiary households across programmes (Figure 2). Ghana's LEAP programme has the largest concentration of elderly beneficiaries, with relatively few adults of working age, few small children, and lots of older children and adolescents. The Zambia CGP benefits a much larger proportion of working age adults with small children.

The varying degree of labour availability likely contributes to explaining the differences in productive impacts observed across programmes. 
While labour-constrained households may hirein labour and carry out limited economic activities, households with available labour are in a better position to take advantage of the cash for productive activities, in both the short and long run.

Access to other assets besides labour can also facilitate the productive use of cash transfers. Numerous stories from the qualitative fieldwork illustrate that households with access to more land, implements and/or education are in a better position to utilise the cash for productive purposes, and will likely progress further along the pathway towards graduation.

\subsection{Programme level enablers of livelihoods transformation}

A second group of factors that can facilitate or inhibit the productive impacts of cash transfers has to do with programme design and implementation features. These include transfer value, transfer predictability and programme messaging.

\section{Transfer value}

The amount of money transferred to a beneficiary household is clearly a factor in the range and intensity of impacts on productive activities. Transfer levels are set following different criteria across countries. Some countries (Kenya in the early phase, Zambia) adopted a flat transfer schedule while others vary the amount in accordance to household size (Kenya at a later stage), number of children (Lesotho) or number of vulnerable people (Ghana). The programmes generally lack mechanisms to adjust the transfer amount on a regular basis for inflation. In Kenya, for example, the real value of the transfer fell by almost 60 per cent because of inflation between 2007 and 2011.

As a result there is a great deal of variation in the value of the transfer as a share of beneficiary households' per capita consumption. In Zambia the relative value of the transfer reached almost 30 per cent of per capita consumption, compared to less than 10 per cent for the Ghana LEAP in its early days. For those countries utilising a flat rate, the per capita value varies by household size. While for average size households the Kenya transfer represented 14 per cent of per capita consumption, the share ranged from 10 per cent to 22 per cent for large and small households, respectively.

\section{Transfer predictability}

A critical feature of cash transfer programmes is to provide income support to poor and vulnerable households in a frequent, regular and predictable manner. The frequency and predictability of cash transfers are important, as this facilitates consumption smoothing, planning of expenditures and moderate risk-taking, in anticipation of future payments. With strong expectations on the reliability of the transfer flow, households can build up assets and precautionary savings that can be used to maintain minimum standards of living during times of hardship. This can incentivise risktaking that is more conducive to income diversification and productivity enhancement. It is also positively associated with the impact of cash transfers on poverty reduction as well as human capital accumulation (Barca et al. 2013).

At the time of their respective evaluations, operational performance varied from country to country and is likely to have influenced how households spend their transfers. In Zambia the transfers were delivered regularly throughout the evaluation period. In Ghana payments were also meant to be bi-monthly, but the schedule suffered major disruptions. The Lesotho CGP was the programme with the least frequent payment schedule (quarterly), yet it was also affected by significant delays.

\section{Messaging}

A third dimension likely to influence productive impacts is the messaging and information provided to beneficiaries regarding the expected use of the resources provided. All programmes considered in this study were unconditional. Yet unconditional transfers often adopt implicit, indirect or soft conditioning or messaging mechanisms that can have important consequences for the impact of the transfer (Schüring 2010; Pellerano and Barca 2014). The Lesotho CGP had especially strong messaging on expenditures towards children's clothes, shoes and related expenses, which resulted in particularly large impacts on these expenditures - possibly to the detriment of spending on more productive activities.

\subsection{Market level enablers of livelihoods transformation}

Transformation in sustainable livelihoods cannot happen without a conducive market environment that provides opportunities for income-generating activities and increases in productivity. The 
nature of the local economy shapes the type and extent of productive impacts of cash transfer programmes. All evaluations covered in this study were conducted primarily in rural areas, in environments where market constraints can be particularly binding due to low population density, difficulty in accessing markets, low levels of public investment and inadequate public infrastructure.

The qualitative fieldwork suggests that where markets were more developed, the effects of cash transfers on livelihood strategies were stronger. The importance of market conditions was generally framed in relation to the availability of factors of production. For example, household agricultural economic investment in Kenya was more prevalent in the Owendo District as compared to Kangundo District, due to the wider availability of land, livestock and labour and the prevalence of sugar-cane cash cropping. In

Kangundo, where economic opportunities within the agricultural economy were more constrained, the cash transfer was used foremost as a safety net mechanism. In Ghana and Kenya, the ability to hire-in labour to work on farms owned by the household was reported as a crucial enabler for beneficiaries to engage in new types of economic activities.

\section{Conclusions}

There is an increasing emphasis in international and national policy debates on the importance of developing explicit graduation strategies in social protection programmes. The notion of graduation is the reflection of a series of different policy discussions: a fear that social assistance creates dependency and laziness amongst beneficiaries, an emphasis on the returns of social protection investment to growth and economic development, the importance of increasing the effectiveness of public expenditure and showing sustainable change.

Graduation is generally not an explicit objective of social cash transfer programmes, and few programmes have developed formal exit policies. However, based on the increasingly available evidence it is becoming possible to examine whether cash transfers are influencing livelihood activities in ways that can put beneficiaries on a sustainable pathway towards graduation.

This article has addressed this issue in a crosscountry comparative perspective, drawing lessons from rigorous quantitative and qualitative impact evaluations across four countries in subSaharan Africa (Ghana, Kenya, Lesotho and Zambia). The study analysed the economic effect of cash transfers on productive activities, focusing particularly on behavioural changes associated with increases in economic productivity and livelihood diversification. It also investigated the factors that may have explained the emergence (or not) of such impacts across the programmes considered.

We find that cash transfers have significant impacts on the livelihoods of beneficiary households, as well as on the communities in which they live. These impacts vary from country to country, and context to context - in Zambia in particular, the cash transfer programme activated a transformative process leading to a stronger engagement of beneficiary households in capital investment for agricultural production and new economic activities. The impacts in Kenya and Lesotho were more selective in nature, while the LEAP programme in Ghana had fewer impacts directly on productive activities, and more on various dimensions of risk management. In each case, the programme increases the likelihood of graduation, and perhaps serves as a pathway to graduation, though it is difficult to see yet where this pathway is going, or how far it can take beneficiary households.

The analysis of the drivers of such observed differences leads to three main conclusions. First, sustainable graduation is not a credible promise for many segments of the population, particularly households with limited labour capacity. For this group the core function of social assistance programmes should remain centred around the protection of minimum standards of living. The increasing focus on graduation should not drive resources away from households in most need of long-term protection (children, the elderly and the disabled). Second, sustainable graduation can be facilitated by specific cash transfer design features. The level of transfers, the predictability of payments and the type of messaging associated with the disbursement are critical factors that can be manipulated by programme implementers to facilitate economic impacts.

Third, sustainable graduation is not a credible promise in the absence of conducive market 
conditions. Cash transfers can relax some liquidity and credit constraints, but cannot replace a holistic economic development strategy. The shape and type of markets, as well as access to and the quality of public services, matter. The degree of market integration and the level of economic dynamism determine the conditions on which cash transfer beneficiary households can access productive inputs (credit, labour, capital assets) but also the strength of the market-based demand for beneficiary households' potential production outputs. Moreover, cash transfers are not a silver bullet - they need to be seen in the context of a strategy of poverty reduction. They require complementary programmes, whether existing or specific add-ons, to sustainably bring households out of poverty.

\section{Notes}

* The views expressed in this publication are those of the author(s) and do not necessarily reflect the views or policies of FAO.

1 Corresponding author. Errors are the responsibility of the authors only, and this article reflects the opinions of the authors and not the institutions with which they are affiliated.

2 The PtoP project (www.fao.org/economic/ptop/ en/) forms part of a larger effort, the Transfer Project (www.cpc.unc.edu/projects/transfer), which is supporting the implementation of impact evaluations of cash transfer programmes in sub-Saharan Africa.

\section{References}

AIR (2013) Zambia's Child Grant Program: 24-month Impact Report, Washington DC: American Institutes for Research (AIR)

Asfaw, S.; Davis, B.; Dewbre, J.; Handa, S. and Winters, P. (2014) 'Cash Transfer Programme, Productive Activities and Labour Supply: Evidence from a Randomised Experiment in Kenya', Journal of Development Studies 50.8: 1172-96

Asfaw, S.; Davis, B.; Dewbre, J.; Federighi, G.; Handa, S. and Winters, P. (2013) The Impact of the Kenya CT-OVC Programme on Productive Activities and Labour Allocation, From Protection to Production Project Report, Rome: FAO

Barca, V.; Hurrell, A.; MacAuslan, I.; Visram, A. and Willis, J. (2013) 'Paying Attention to Detail: How to Transfer Cash in Cash Transfers', Enterprise Development and Microfinance 24.1: 10-27
Moving forward, two main challenges can be identified. First, it is important to refine the notion of graduation, distinguishing it from programme exit, but also distinguishing between a short- and long-term horizon to graduation policies, the institutional context of operation and the market context. It is also important to conceive graduation in the context of a social protection system, rather than one of single programmes. Finally, more research is needed on the determinants of sustainable graduation, including the starting conditions and the role of other household, programme and market characteristics.

3 The results discussed in this article are taken from Handa et al. (2013), OPM (2012) and Thome et al. (2014a) for Ghana; Asfaw et al. (2013), Asfaw et al. (2014), OPM (2014a) and Taylor et al. (2013) for Kenya; AIR (2013), Daidone et al. (2014b) and Thome et al. (2014b) for Zambia; and Daidone et al. (2014a), Pellerano et al. (2014), OPM (2014b) and Taylor, Thome and Filipski (2014) for Lesotho.

4 Similar results were found for the Mchinji pilot of the Malawi Social Cash Transfer programme (Covarrubias, Davis and Winters 2012).

Covarrubias, K.; Davis, B. and Winters, P. (2012) 'From Protection to Production: Productive Impacts of the Malawi Social Cash Transfer Scheme', Journal of Development Effectiveness 4.1: 50-77

Daidone, S.; Davis, B.; Dewbre J. and Covarrubias, K. (2014a) Lesotho's Child Grant Program: 24-month Impact Report on Productive Activities and Labour Allocation, From Protection to Production Project Report, Rome: FAO

Daidone, S.; Davis, B.; Dewbre, J.; GonzálezFlores, M.; Handa, S.; Seidenfeld, D. and Tembo, G. (2014b) Zambia's Child Grant Program: 24-month Impact Report on Productive Activities and Labour Allocation, From Protection to Production Project Report, Rome: FAO Garcia, M. and Moore, C. (2012) The Cash Dividend. The Rise of Cash Transfer Programs in Sub-Saharan Africa, Washington DC: World Bank 
Handa, S.; Park, M.; Darko Osei, R.; Osei-Akoto, I.; Davis, B. and Daidone, S. (2013) Livelihood Empowerment Against Poverty Program Impact Evaluation, Chapel Hill NC: UNC Carolina Population Center

OPM (Oxford Policy Management) (2014a) Qualitative Research and Analyses of the Economic Impact of Cash Transfer Programmes in Sub-Saharan Africa. Kenya Country Case Study Report, From Protection to Production Project Report, Rome: FAO

OPM (Oxford Policy Management) (2014b) Qualitative Research and Analyses of the Economic Impact of Cash Transfer Programmes in Sub-Saharan Africa. Lesotho Country Case Study Report, From Protection to Production Project Report, Rome: FAO

OPM (Oxford Policy Management) (2012) Qualitative Research and Analyses of the Economic Impact of Cash Transfer Programmes in Sub-Saharan Africa. Ghana Country Case Study Report, From Protection to Production Project Report, Rome: FAO

Pellerano, L. and Barca, V. (2014) Does One Size Fit All? The Conditions for Conditionality in Cash Transfers, Oxford Policy Management Working Paper, Oxford: OPM

Pellerano, L.; Moratti, M.; Jakobsen, M.; Bajgar, M. and Barca, V. (2014) The Lesotho Child Grants Programme Impact Evaluation: Follow-up Report, Oxford: Oxford Policy Management, Government of Lesotho, UNICEF/FAO

Sabates-Wheeler, R. and Devereux, S. (2013)

'Sustainable Graduation from Social Protection Programmes', Development and Change 44.4: 911-38
Schüring, E. (2010) Conditions, Conditionality, Conditionalities, Responsibilities - Finding Common Ground, Maastricht Graduate School of Governance Working Paper 014, Maastricht: Maastricht University

Slater, R. and McCord, A. (2009) Social Protection, Rural Development and Food Security: Issues Paper on the Role of Social Protection in Rural Development, London: ODI

Taylor, J.E. (2013) A Methodology for Local Economywide Impact Evaluation (LEWIE) of Cash Transfers, From Protection to Production Project Report, Rome: FAO

Taylor, J.E.; Thome, K. and Filipski, M. (2014) Evaluating Local General Equilibrium Impacts of Lesotho's Child Grants Programme, From Protection to Production Project Report, Rome: FAO

Taylor, J.E.; Kagin, J.; Filipski, M. and Thome, K. (2013) Evaluating General Equilibrium Impacts of Kenya's Cash Transfer Programme for Orphans and Vulnerable Children $(C T-O V C)$, From Protection to Production Project Report, Rome: FAO

Thome, K.; Taylor, J.E.; Davis, B.; Darko Osei, R. and Osei-Akoto, I. (2014a) Local Economy-wide Impact Evaluation (LEWIE) of Ghana's Livelihood Empowerment Against Poverty (LEAP) Programme, From Protection to Production Project Report, Rome: FAO

Thome, K.; Taylor, J.E.; Kagin, J.; Davis, B.; Handa, S.; Seidenfeld, D. and Tembo, G. (2014b) Local Economy-wide Impact Evaluation (LEWIE) of Zambia's Child Grant Programme, From Protection to Production Project Report, Rome: FAO 